\title{
Fundando a nação: a representação de um Brasil barroco, moderno e civilizado*
}

\section{Márcia Chuva}

Na conferência de abertura do "Congresso do Barroco no Brasil - Arquitetura e Artes Plásticas”, realizado em Ouro Preto, em 1981, Afonso Ávila reconhecia o barroco brasileiro como um "vínculo de civilização que nos irmana aos povos do Ocidente". Com isso, atualizava as concepções que fundamentaram as práticas de preservação cultural do Brasil, comparando Aleijadinho e Oscar Niemeyer - Ouro Preto e Brasília - como "algumas das grandes pontes que, ligando passado e presente, igualmente comunicam ao mundo, sem perda da individualidade nacional, uma perene universalidade de nossa arte, de nossa cultura." ${ }^{1}$ Dentre essas concepções, a questão do pertencimento à civilização ocidental foi talvez a mais significativa na configuração que tomou o processo de invenção de um "patrimônio nacional" no Brasil. Os cânones da arte brasileira e sua universalidade foram construídos de modo eficaz, com a consagração de uma associação inédita até então entre as formas e princípios renovadores do barroco e a produção arquitetônica moderna. Isso se deu, privilegiadamente, no âmbito da ação de proteção do patrimônio histórico e artístico nacional.

Nos anos 30 do século XX, um intenso trabalho de construção da nação foi inaugurado como parte do projeto de modernização do ministro da Educação e Saúde, Gustavo Capanema, homem forte do governo Vargas. Nesse projeto, a noção de interesse público prevaleceria, política ou simbolicamente, ante os interesses individuais. Foi este um dos caminhos em que se tornou possível promover o pensamento de unidade nacional, especialmente dentro do Estado Novo: era preciso escapar do individual, que era fragmentário, em busca do público ou do bem comum, unificador. Somente a unidade das origens e a ancestralidade comum de toda a nação

* Artigo recebido em março de 2003 e aprovado em maio de 2003.

TOPOI, v. 4, n. 7, jul.-dez. 2003, pp. 313-333. 
deveriam servir para ordenar o caos, encerrar os conflitos, irmanar o povo e civilizá-lo. As práticas de preservação cultural foram inauguradas no Brasil no bojo desse projeto, a partir da criação do Serviço do Patrimônio Histórico e Artístico Nacional - o SPHAN, em 1937.

Intelectuais de peso que moldaram o patrimônio histórico e artístico brasileiro, como Lucio Costa, Rodrigo Melo Franco de Andrade e Carlos Drummond de Andrade - embora consagrados por outras vias de reconhecimento e inserção social - tendo em mãos seus passaportes para a modernidade - atuaram decisivamente dentro do governo Vargas, especialmente no Estado Novo. Esses intelectuais tornaram-se, a um só tempo, funcionários dedicados do SPHAN, onde consolidaram todo um pensamento acerca do patrimônio histórico e artístico brasileiro, e os gênios fundadores de uma nação moderna, que se identificavam na crença comum que possuíam acerca da universalidade da cultura e da arte. Com base nessa crença, formularam as teses acerca do patrimônio cultural brasileiro que inseriram o Brasil no mundo civilizado.

Seria interessante, então, observá-los sob uma ótica que ressaltasse os vínculos entre suas expectativas acerca da nação da qual foram também artífices. Nomeá-los "modernistas" não seria suficiente, pois os debates em torno da "criação da nação", que estiveram presentes no modernismo dos anos 20, e foram incorporados às malhas do Estado após 1930, acabaram por evidenciar diferenças cruciais entre as várias correntes que se formaram, constituindo grupos por vezes antagônicos em relação às suas visões de mundo e ao projeto de nação em disputa.

As diferentes soluções projetadas para os imensos desencontros, contrastes e diversidades presentes no território brasileiro levavam a diferentes vias explicativas da "identidade nacional". Nesse sentido, a questão da valorização, ou não, das diferenças regionais como constituidoras da identidade nacional, que abriu um leque amplo de debates em torno das origens da nação, tornou-se um divisor de águas para as concepções que fundamentariam, posteriormente, as práticas de preservação cultural no SPHAN: para alguns modernistas, as características regionais eram sinal de atraso e obstáculo à atualização da cultura brasileira e, para outros, ao contrário, eram depositárias da verdadeira identidade. Com relação a tais teses, como veremos, Rodrigo Melo Franco de Andrade, Carlos Drummond de An- 
drade e Lucio Costa identificavam-se profundamente entre si, pela crença na universalidade - e, conseqüentemente, na origem comum - da cultura e da arte, sendo este um ponto crucial na concepção de nação que se consagrou no Brasil a partir do SPHAN.

Rodrigo Melo Franco de Andrade, em 1952, rememorando essa época, atualizava seu pertencimento a um certo grupo de modernistas que denominou a "quarta corrente" - nome que faz referência aos outros grupos existentes, um deles organizado em torno de Graça Aranha, Ronald de Carvalho e Renato Almeida; outro, os "verde-amarelos", tendo Plínio Salgado, Cassiano Ricardo e Menotti Del Picchia à frente; ou ainda, o grupo de tendência esteticista de Guilherme de Almeida. ${ }^{2}$

Como editor da Revista do Brasil, transformou-a num "órgão do modernismo" segundo suas palavras, ao contar com as fortes relações de amizade mantidas com Prudente de Moraes Neto, Sérgio Buarque de Holanda e Afonso Arinos de Melo Franco, todos eles integrantes dessa quarta corrente, que se tornaram freqüentadores assíduos de seu Gabinete no SPHAN e também autores da Revista do SPHAN. ${ }^{3}$ Eles formaram o grupo modernista reunido no Rio de Janeiro, que diversificou o movimento, a partir de 1924, integrando novas redes, às quais mineiros como Carlos Drummond - que ainda permanecia em Belo Horizonte - seriam também atraídos. Esse grupo, que havia criado $A$ Revista, publicada em Belo Horizonte entre 1925-1926, representava a vertente universalista e cosmopolita do modernismo mineiro. ${ }^{4}$

Em 1927, num artigo na Revista do Brasil, Rodrigo Melo Franco de Andrade confrontava-se abertamente com Plínio Salgado, posicionandose contrariamente ao indianismo que fundamentou, em boa medida, as teses geograficizantes das origens da "cultura nacional" da corrente modernista "verde e amarelo". Sua clareza em relação à inexistência da nação brasileira e à necessidade de se investir na sua constituição ficou expressa nesse artigo:

O Sr. Plínio Salgado não pode saber se quando chegarmos a constituir uma nação, o elemento preponderante na formação desta será o tupi ou o japonês. Não convém, portanto, brigar com seus amigos 'verde e amarelos' por causa do índio. ${ }^{5}$ 
Diante do longo trabalho que estava por se realizar para que a nação brasileira se constituísse, Rodrigo Melo Franco considerava fundamental, ao mesmo tempo, reafirmar uma herança européia - portuguesa - e, em contrapartida, negar uma possível herança indígena. Argumentava que as frágeis construções de madeira haviam sido logo substituídas pelas edificaçôes mais duradouras que imprimiram às primeiras povoaçôes sua "fisionomia peculiar", considerando

... injustificável [...] que os povoadores portugueses do Brasil tivessem vindo aprender com nossos indígenas a erigir construções de madeira, técnica essa muito antiga e corrente na Europa e na península. Nem se pode admitir que os colonos europeus se resignassem a utilizar por longos anos construçōes extremamente frágeis e toscas." ${ }^{\circ}$

A posição que Rodrigo Melo Franco tomou nesse debate delinearia, ou melhor, daria propriamente uma forma ao pensamento que se consolidou no SPHAN, ao buscar, sem regionalismos, constituir a fisionomia do Brasil que seria apresentada, no âmbito das relações internacionais que estabelecia, para garantir um pertencimento ao mundo das nações modernas.

O grupo que atuaria junto ao SPHAN, a partir de 1937, foi marcado por essa forte experiência dos anos 20 , partilhando vivências comuns e, sem dúvida, pelo drama da modernidade vivido por esses intelectuais e por suas contradições. Rodrigo Melo Franco de Andrade foi um elo fundamental de integração de experiências e amizades entre mineiros e paulistas em torno de sua mesa no Gabinete do SPHAN, no Rio de Janeiro, como primeiro diretor do Serviço, desde a fase experimental, em 1936, permanecendo até 1967, e peça-chave na articulação política e na constituição das redes de agentes em todo o território brasileiro. Sua vida pessoal confundiu-se com o que chamava sua missão, como personagem de destaque que foi nesse novo campo de intervenção social: consolidar uma lei e um serviço público de salvaguarda do patrimônio nacional, sem perder de vista a inserção brasileira nas redes internacionais, numa espécie de diplomacia cultural por ele exercida.

Também Carlos Drummond de Andrade seria um legítimo representante de tais idéias. Concebidas, como dissemos, a partir da crença na universalidade da arte e da cultura e preocupadas com um provincianismo que 
limitava as possibilidades de inserção no quadro internacional, as idéias às quais se alinhava Drummond vinculavam-se a uma matriz iluminista e racionalista do pensamento.

Em relação às teses que fundamentaram as práticas do SPHAN, o contraponto entre os dois grandes escritores modernos - o paulista Mário de Andrade, também partícipe da fundação do SPHAN, e o mineiro Carlos Drummond de Andrade - colocou em evidência as concepções universalizantes de Drummond e as profundas distinçôes em relação ao pensamento de Mário de Andrade. Este pretendia encontrar categorias classificadoras que, através do conhecimento, pudessem enquadrar a cultura brasileira múltipla e plural. Sustentava a crença no valor da diversidade cultural brasileira que, reunida ou amalgamada, faria uma nova síntese. ${ }^{7}$ Essa possibilidade de valorização de diferentes manifestaçôes culturais como identificadoras da "brasilidade" vai de encontro às idéias de Drummond, em que a inserção no mundo civilizado se daria, principalmente, pela identificação de uma arte brasileira que pudesse se enquadrar na classificação tradicional da história da arte no mundo ocidental.

Além dessas diferenças, a geração de Drummond transitava pela literatura e pela política, como afirma Bomeny, "não pela compulsão missionária de Mário de Andrade, mas por uma experiência de oficialidade que se acumulava naquele conjunto de intelectuais, 'a geração dos chefes de gabinete." Ainda que Mário de Andrade tenha retornado a São Paulo como funcionário da sede regional do SPHAN, caiu num ostracismo rancoroso ou desiludido, até sua morte prematura em 1945. Por sua vez, Carlos Drummond de Andrade foi absorvido por Rodrigo Melo Franco de Andrade como funcionário do SPHAN, com o fim do governo Vargas e de sua gestão como chefe de gabinete de Capanema. No SPHAN, tornou-se um barnabé, como ele próprio se denominava. Ao assumir a Seção de História, responsabilizava-se, segundo o desejo de Rodrigo, em carta para Lucio Costa, por elaborar um plano de organização compreendendo arquivo e biblioteca da DPHAN, subordinada à Diretoria de Estudos e Tombamento, dirigida por Lucio Costa. ${ }^{9}$ Cabia a Drummond a inscrição nos Livros de Tombo dos bens selecionados para tombamento pelo SPHAN, bem como a constituição de um acervo para a biblioteca e a formulação de uma lógica para o arquivamento de toda a documentação produzida no órgão, 
constituindo, progressivamente e de modo peculiar, um acervo de documentação variada acerca do patrimônio histórico e artístico nacional, arquivado pelo endereço do bem cultural. ${ }^{10}$ Essa escolha se deu, sem dúvida, em função das necessidades da lida diária dos técnicos do SPHAN. Carlos Drummond de Andrade aposentou-se no SPHAN, mas declinou sempre ao convite de escrever na Revista do SPHAN, mantendo-se fiel a sua escolha - em favor de sua própria arte.

\section{Lucio Costa no SPHAN: a moderna profissão do arquiteto}

Lucio Costa, vanguardista da arquitetura moderna no Brasil, não teve envolvimento com qualquer dos diferentes grupos ou correntes modernistas dos anos 20. No entanto, suas concepçōes abriram uma nova frente no mundo do modernismo, com uma aproximação fecunda entre as concepções de arte e visões de mundo daqueles integrantes da citada quarta corrente do modernismo, com as suas "razões da arquitetura", de 1934, na perspectiva universalista da cultura e da arte. ${ }^{11}$

Nos anos 30, Lucio Costa tornou-se um dos personagens fundamentais no processo de profissionalização do arquiteto, no que se refere à formulação de uma fala própria à categoria. Já era então um arquiteto de renome, tendo conquistado prêmios em concursos nacionais e internacionais. Por indicação de Rodrigo M. F. de Andrade, na ocasião chefe de Gabinete do Ministro da Educação e Saúde Pública, Francisco Campos, assumiu, em 8/12/1930, a direção da Escola de Belas Artes - EBA.

Implantou, então, reformas na Escola, que passou a comportar dois cursos didaticamente autônomos: um de Arquitetura e outro de Pintura e Escultura, chamando Gregori Warchavchik, que havia sido o introdutor da arquitetura moderna no Brasil, para lecionar Composição de Arquitetura. ${ }^{12}$

Para o curso de Pintura e Escultura, criou o "Salão Livre", onde reuniu artistas não consagrados pelas exposições oficiais ${ }^{13}$. Os antigos professores, afastados, abriram campanha ostensiva contra as reformas impostas. $\mathrm{Na}$ contra-ofensiva, os estudantes promoveram uma greve de seis meses se solidarizando com Lucio Costa. Conseguiram, com isso, manutenção de pontos básicos da reforma, mas Lucio Costa foi obrigado a se afastar da direção da escola em 19 de setembro de 1931. ${ }^{14}$ Nessa ocasião, Lucio Costa 
e Gregori Warchavchik projetaram a "Vila Operária da Gamboa”, no Rio de Janeiro. Entre 1933 a 1936, Lucio Costa esteve associado ao arquiteto Carlos Leão, tendo sido, também, professor da Universidade do Distrito Federal, no ano de 1935.

Mas, reflexos talvez de sua breve gestão, em 1932, o Ministro Washington Pires promoveu a reorganização das disciplinas, a pedido da Congregação da EBA, com a criação de novas cadeiras científicas, artísticas e de estudos de Urbanismo. Já em 1933, foi criado primeiro instrumento legal de regulamentação das profissões de engenheiro, arquiteto e agrimensor, o que demarcou o mercado de trabalho dessas profissóes. ${ }^{15}$

Em 1935, realizou-se o concurso para seleção de projeto para construção do prédio do Ministério da Educação e Saúde, em que foi vencedor o projeto de Arquimedes Memória, professor catedrático e diretor da Escola de Belas Artes desde a saída de Lucio Costa. No entanto, seu projeto não foi realizado e, em março de 1936, Capanema convidava Lucio Costa para elaborar uma nova proposta. ${ }^{16}$ Lucio Costa constituiu então uma equipe, junto com alguns arquitetos desclassificados no concurso: Carlos Leão, Jorge Moreira, Affonso Eduardo Reidy, Oscar Niemeyer e Ernani Vasconcellos. Com apoio de Carlos Drummond de Andrade (então Chefe de Gabinete de Capanema), Mário de Andrade, Rodrigo Melo Franco de Andrade e Manuel Bandeira (já engajados no SPHAN), Lucio Costa convenceu diretamente Vargas, sob os auspícios de Capanema, a convidar o ilustre arquiteto moderno para orientar a confecção de um novo projeto, o suíço Le Corbusier, que viajou para o Brasil a bordo do dirigível Zeppelin. O prédio do Ministério tornou-se um dos marcos decisivos no reconhecimento oficial da arquitetura modernista no Brasil e no mundo.

O período estadonovista possibilitou a consolidação e oficialização da vertente modernista da arquitetura, que teve na obra e na figura de Lucio Costa seu maior paradigma e sua maior liderança. Criou as possibilidades de sua institucionalização, com a formulação de um discurso perfeitamente enquadrado nas questões mais presentes daquele momento, até mesmo no que diz respeito à recuperação da tradição, sempre de acordo com sua visão de mundo moderna. Ou seja, sem imitá-la ou reproduzi-la, mas no que ela tinha de melhor: a pureza das formas, o lirismo, o equilíbrio. 
Foi a partir de 1945 que se deu a proliferação das faculdades de Arquitetura no Brasil. ${ }^{17}$ Reservou-se, enfim, um campo específico ao novo profissional - $\mathrm{o}$ arquiteto. A arquitetura distinguiu-se, paulatinamente, no campo de disputa sócio-profissional travado com a engenharia civil. Essas lutas de representação viriam a caracterizar a profissão do arquiteto como capaz de propor uma adaptação permanente ao contexto sociocultural em que a arquitetura fosse produzida, voltando-se para a leitura das condições sociais e tecnológicas existentes no tempo e no espaço em que se concretizaria. Considerando-se a amplitude própria à formação, o habitus do arquiteto pode ser pensado a partir da soma de cada uma das especialidades do artista, do engenheiro, do historiador e do sociólogo. ${ }^{18}$

Um dos traços mais característicos dessa orientação - que se firmou como "própria do arquiteto" - foi justamente a intenção de uma abordagem multifacetada, situando-se a meio caminho entre a técnica, a arte e a história. $\mathrm{O}$ estudo das técnicas não deveria desvincular-se do exame das condições em que estas deveriam ser utilizadas. Palavras como "racionalização", "verdade", "autenticidade", "legitimidade", passariam a integrar necessariamente o seu vocabulário, que, no Brasil, se constituiu no bojo da consagração da vertente modernista na arquitetura. Nesse contexto, os arquitetos se auto-atribuíram o sentido da modernidade, como algo intrínseco à profissão, visando à retomada dos aspectos peculiares à experiência brasileira, e enriquecendo-se da racionalidade contemporânea, com utilização efetiva das novas tecnologias. Isso fica bastante evidente ao se observarem arquitetos dessa vertente atualizando esse tema, fazendo questão de serem tratados, ainda hoje, não por modernistas, mas por "modernos", a fim de não serem identificados a um estilo arquitetônico de época, mas representantes de princípios universais e valores atemporais. ${ }^{19}$ Para Lucio Costa, a arquitetura daria materialidade à nação, e seria esta a função primordial do SPHAN - dar concretude à nação, não somente desvendando a todos os brasileiros aquilo que, embora existente, se encontrava escondido, mas, também, construindo efetivamente essa materialidade.

Lucio Costa assumiria papel central dentro do SPHAN, por um lado, ao inter-relacionar três questões fundamentais, na época, que demarcaram a história do Serviço e o lugar que o arquiteto assume dentro do SPHAN: as práticas de preservação cultural, a produção arquitetônica moderna e a 
formação profissional do arquiteto. Assim, foi capaz de reunir, a um só tempo, os papéis de principal mentor do modernismo em arquitetura no Brasil, de formalizador das bases conceituais que caracterizariam a profissão do arquiteto, e de formulador das posturas e concepçóes do SPHAN, inclusive com relação à restauração do patrimônio arquitetônico, como profissional de carreira desde 1938. Desse modo, em momentos cruciais dentro do Serviço, foi delineado um mapa de possibilidades do que viria a se tornar patrimônio histórico e artístico brasileiro.

Ao ocupar esse lugar, Lucio Costa fundaria um novo tempo para a produção arquitetônica brasileira - moderna e herdeira da "boa tradição"que constituiu uma verdadeira "escola". Essa "escola" formou e forma até hoje profissionais que disputam a herança não só da primeira geração de modernistas brasileiros - cujos representantes máximos são o próprio Lucio Costa e Oscar Neimeyer -, mas também da segunda geração, que se organizou em torno desses já consagrados: os arquitetos da Novacap, os construtores da utopia, a cidade moderna de Lucio Costa. Esses jovens arquitetos também aparelharam-se dentro do SPHAN, como funcionários do Serviço, que se tornou um mercado de trabalho privilegiado e de grande prestígio para a categoria profissional do arquiteto.

Lucio Costa torna-se, concretamente, o elo entre o moderno e a tradição, construindo essa associação, conceitualmente, através de artigos publicados na Revista do SPHAN, das restaurações que o SPHAN executou sob sua orientação, das informações que produziu como técnico do Serviço acerca de solicitações de tombamento.

Dentre as várias ações implementadas a partir da política de proteção ao patrimônio nacional, a edição da Revista do Patrimônio foi muito bemsucedida no sentido de construir uma identidade nacional que, associadamente, revelasse uma nação moderna e pertencente ao mundo civilizado, podendo estabelecer o Brasil em pé de igualdade nas redes internacionais de trocas simbólicas em funcionamento e circulação naquele momento. Com base nessas concepçôes, o patrimônio cultural brasileiro teve reconhecimento mundial, inserindo o Brasil na universalidade da arte européia e ao mesmo tempo garantindo-lhe particularidades. 


\section{Lucio Costa na Revista do Patrimônio, "menina dos olhos" de Rodrigo}

A “arte brasileira” era inconfundível, posto que, apesar de inserida dentre os valores universais, possuía especificidades, onde a apropriação "popular" do erudito havia trazido o imprevisto, o criativo, o novo: uma nação nova estava sendo construída. Além da materialidade dos monumentos, portanto, uma outra realidade física estava sendo construída com a produção de livros, onde se afirmava que o Brasil era uma nação porque possuía cultura, era civilizado porque suas raízes advinham da arte universal.

A política editorial do SPHAN foi marcada por uma produção discursiva descritiva e classificadora do patrimônio histórico e artístico nacional, capaz de conquistar legitimidade para prescrever os atributos desse patrimônio e para fixar um mapa de possibilidades. Com ela, o SPHAN passaria a balizar e polarizar os debates sobre essa temática, fazendo com que, ao se falar de preservação cultural no Brasil, se tornasse impossível não se remeter à sua produção, ainda que para criticá-la ou questioná-la.

A Revista do Patrimônio - a "menina dos olhos" de Rodrigo, segundo Lucio Costa - teve no bojo do seu projeto a preocupação com a "construção" de uma arte brasileira que se enquadrasse nos padrôes universais. Augusto C. da Silva Telles ${ }^{20}$, ao apresentar um panorama bastante completo dos estudos das artes e da arquitetura barroca do período colonial no Brasil e da bibliografia existente, destacou a inexistência de produção acerca do assunto até a criação do SPHAN, quando se iniciou imenso investimento na elaboração de estudos apoiados em critérios científicos, com base documental e crítica, com uma campanha de pesquisas e levantamento documental iniciada por Rodrigo Melo Franco, para publicação na Revista. ${ }^{21}$ Antes de 1937, a produção artística brasileira permanecia "à margem da preocupação da grande maioria dos historiadores e dos críticos de arte europeus e norte-americanos" 22 , tendo sido alguns dos artigos publicados na Revista do SPHAN, nos anos 30 e 40, fundadores no tratamento do assunto. ${ }^{23}$ Acreditava, no entanto, terem sido historiadores estrangeiros os primeiros a realizarem sínteses gerais da arquitetura barroca brasileira. Esses historiadores, como, por exemplo, o americano Robert Smith, também autor da Revista no período, ${ }^{24}$ dariam legitimidade e visibilidade interna- 
cional ao patrimônio brasileiro, por se alinharem às concepções que fundamentavam a existência do barroco no Brasil, em especial na chamada "arquitetura de interior" presente nas igrejas setecentistas mineiras.

A Revista do Patrimônio, embora não fosse uma publicação de luxo, tinha cuidados gráficos, e era recheada de fotografias e desenhos, tendo conquistado, em 1946, o "diploma de honra” na Segunda Exposição Internacional de Publicações Periódicas, realizado pela Biblioteca Pública de Santiago Alvarez da Escola Provincial de Artes Plásticas Tarascá, em Cuba, em que concorreram 1.711 publicações de todo o mundo. ${ }^{25} \mathrm{O}$ jornal A Manhã, de 21 de janeiro de 1946, noticiava que alguns de seus números já estavam esgotados e considerava que "a alta recompensa, de projeção internacional, obtida em Cuba, vem confirmar o crédito que a excelente revista vem alcançando desde seu lançamento nos meios culturais do país e do estrangeiro, e estão por isso de parabéns o seu diretor e todos os seus colaboradores." 26

Ela foi inaugurada visando demarcar um espaço para uma produção de excelência. No no 1 da Revista, de 1937, quatro artigos fizeram uma espécie de apresentação, traçando um panorama geral tanto de diferentes tipos de patrimônio histórico e artístico nacional, quanto das possibilidades de sua proteção, das formas e dos meios para executá-la, com especialistas com atuação profissional variada, configurando uma diversidade de objetos e conhecimentos.

Rodrigo Melo Franco de Andrade expôs no Programa da Revista que não se tratava de iniciativa de propaganda do Serviço e que apoiava-se na contribuição dos "doutos nas matérias relacionadas com sua finalidade". Seu objetivo era, primordialmente, divulgar "o conhecimento dos valores de arte e de história que o Brasil possui e contribuir empenhadamente para seu estudo." 27

Gilberto Freyre escreveu Sugestôes para o estudo da arte brasileira em relação com a de Portugal e das Colônias. Para Freyre, havia um poder de persistência admirável da produção artística colonial que reafirmava a noção de nação constituída, primordialmente, pela cultura portuguesa. Além da arquitetura, Freyre ressaltava, em diversos outros fazeres e ofícios, que

[...] a força criadora do português, em vez de se impor, com intransigência imperial, ligou-se no Brasil ao poder artístico do índio e do negro e, mais 
tarde, ao dos outros povos, sem entretanto, desaparecer: conservando-se em quase tudo o elemento característico. ${ }^{28}$

O artigo de Mário de Andrade, intitulado A Capela de Santo Antônio, embora sem perfil programático, tinha uma caráter conceitual, ao definir um certo entendimento de "valor histórico", utilizado, via de regra, nas classificações do patrimônio nacional protegido pelo Serviço:

O critério para um trabalho proveitoso de defesa e tombamento do que o passado nos legou, tem de se pautar, no Estado de São Paulo, quase exclusivamente pelo ângulo histórico. [...] Tem de ser histórico, e em vez de se preocupar muito com beleza, há de se reverenciar e defender especialmente as capelinhas toscas... ${ }^{29}$

Também no número 1 da Revista, Lucio Costa escreveu Documentação Necessária, referindo-se à necessidade de se recuperar a "boa tradição", pelo estudo da nossa antiga arquitetura civil e nela, particularmente, a casa, que caracterizou de forma bastante peculiar:

Feita de 'pau' do mato próximo e da terra do chão, como casas de bicho, servem de abrigo para toda família - [...] faz mesmo parte da terra como formigueiro, figueira-brava e pé de milho - é chão que continua... Mas justamente por isso, por ser coisa legítima da terra, tem para nós, arquitetos, uma significação respeitável e digna... ${ }^{30}$

Os adjetivos que o autor atribuía à arquitetura pareciam subjetivá-la, levando o leitor a uma identificação dela com os atributos da "raça" - o autêntico brasileiro, filho da terra. Valorizava, assim, a inventividade nas formas peculiares de apropriação, que vieram a caracterizar a arquitetura popular brasileira, processo desenvolvido tão "naturalmente" que também a própria nação e os membros que a constituíssem genuinamente seriam "naturais". Essa forma de construir era a "boa tradição" que não podia ser perdida e, como disse Rodrigo Melo Franco de Andrade, o arquiteto moderno Lucio Costa era seu "herdeiro legítimo".

A preocupação central estava voltada para a valorização do passado colonial, representando as origens da nação, conferindo-lhe uma ancestralidade que deveria referenciar-se numa matriz portuguesa, mas que, a partir dela, configuraria um universo tipicamente brasileiro. Nos números 
subseqüentes da Revista, a chave de entendimento esteve no incentivo à produção e na publicação efetiva de estudos acerca da classificação da arte brasileira e seu patrimônio colonial, na categoria de arte barroca, pois era esta que iria vincular o Brasil à história da arte universal. ${ }^{31}$

Mas a participação mais significativa de Lucio Costa foi, sem dúvida, através do seu artigo seminal intitulado Arquitetura Jesuítica no Brasil, na Revista do Patrimônio no 5, de 1941. Nele, Lucio Costa formulou uma classificação da arte brasileira, que iria, não só orientar a prática de restauração no Brasil, mas, principalmente, esclarecer o que seria a arte barroca brasileira. Para Costa, ela significava não apenas um estilo, mas abrangia todo um sistema, uma

"[...] verdadeira confederação de estilos - uma commonwealth barroca, poder-se-ia dizer, [...] pois são diferenciados entre si mas mantêm uma norma comum de conduta em relação aos preceitos e módulos renascentistas. [...] a maior parte das manifestações de arte compreendidas entre a última fase do Renascimento e o novo surto classicista de fins do século XVIII e, no Brasil, princípios do XIX. ${ }^{32}$

A “arquitetura tradicional” foi classificada em tipos de manifestações de arte barroca no Brasil, cronologicamente colocados em quatro períodos essenciais, correspondendo cada um deles a um estilo determinado: $1^{\text {a }}$ fase, classicismo barroco, de fins do século XVI e primeira metade do XVII, que foi importado de Portugal; 2a fase, romanicismo barroco, de meados e segunda metade do século XVII e princípios do XVIII, correspondendo às "versões populares" da primeira fase, com dois únicos exemplares em São Paulo, inventariados por Mário de Andrade, desde 1937; 3ª fase, goticismo barroco, da primeira metade e meados do século XVIII; e a 4 a fase, renascimento barroco, da segunda metade do século XVIII e princípios do XIX. ${ }^{33}$

Trata-se de uma verdadeira tomada de posição, especialmente sob o aspecto da determinação de uma classificação evolutiva, que de forma sistêmica consagrou uma tipologia que seria reconhecida não somente no interior do Serviço, mas pela própria historiografia da arte no Brasil - uma historiografia da "civilização material brasileira". Instaurava-se então um tempo propriamente brasileiro, diferente do português, embora dele advindo. Conforme Lucio Costa, a produção arquitetônica colonial brasilei- 
ra se enquadrava numa classificação universal, "obedecendo a um processo evolutivo normal, de natureza, por assim dizer, fisiológica” ${ }^{34}$

Do primeiro estilo - o mais caracterizadamente jesuítico - até ao estilo mineiro da última fase, cuja obra-prima é a capela-mor da Igreja de São Francisco de Assis, em Ouro Preto, estilo apenas alcançado pelos padres, as transformaçóes sucessivas repetem, curiosamente e na mesma cadência, as várias etapas que percorreu o conjunto da arte européia, na sua evolução da idade clássica à Renascença, através dos estilos medievais românico e gótico. ${ }^{35}$

O Brasil repetia as fases da periodização da Europa civilizada, na qual se inseria e da qual se diferenciava. No "caso brasileiro" foi na composição e na talha dos retábulos de altar que se deu com maior nitidez essa extraordinária profusão e variedade de estilos peculiar do barroco - elementos esses considerados também arquitetura, porém "de interior".

Essa cronologia comportava, em não mais de 250 anos (fins do século XVI e começo do XIX), as fases do processo civilizatório do mundo europeu ocidental: o clássico grego; o românico; o gótico; e o renascentista. Todas essas fases estavam reunidas por uma adjetivação comum a todas elas no Brasil - o barroco -, que colocava as origens da nação brasileira sincronizadas com a história do mundo "civilizado". Aparentemente queimando etapas, essa cronologia sintetizava experiências e tirava-lhes o sumo essencial de forma a atualizar a nova nação que, num curto espaço de tempo, alcançava o tempo do velho mundo. Estavam sendo forjadas uma ancestralidade e uma herança, que permitiriam à nação prosseguir acompanhando, sincronicamente, a partir de então, a evolução da "arte universal".

Evidentemente, uma determinada estética modernista atravessou o estudo de Lucio Costa, evidenciando um engajamento profundo com essa contemporaneidade e visão de mundo moderna. Lucio Costa promoveu então uma apologia do barroco, através da sua estética contemporânea e, ao mesmo tempo em que encontrava as "especificidades brasileiras", preocupava-se permanentemente em introduzi-las no processo civilizatório europeu. Essa identidade foi forjada pelo "espírito moderno":

[...] o estilo que caracterizou as grandes matrizes mineiras, e já tratado pela nova geração modernista da segunda metade daquele século[XVIII], isto é, 
dos artistas que ergueram as igrejas de irmandades - como 'antigo' e de 'gosto gótico', conforme se vê, entre tantos outros documentos [...]. Esse novo estilo, 'moderno', como então se dizia, data da segunda metade do século XVIII [...] . Corresponde a um verdadeiro Renascimento, com a volta às composições mais claras e arrumadas da primeira época.[...] Do exposto resulta que se pode razoavelmente falar de um 'classicismo barroco', de um 'romanicismo' e de um 'goticismo' barrocos e, finalmente, de um 'renascimento barroco'. ${ }^{36}$

\section{Mapa de um Brasil barroco, moderno e civilizado}

Para recuperar para a nação a posse ou o domínio das suas origens, o patrimônio deveria manter-se e/ou voltar ao seu estado primitivo, devolvendo à nacionalidade um vigor perdido. Para tanto, os vestígios materiais deveriam também ser identificados, revelando à nação sua origem barroca, o que se daria através das práticas de restauração: as obras de restauro empreendidas buscavam um tempo apropriado ao qual o imóvel deveria retornar - o tempo colonial - sendo justamente nesse ponto que, mais uma vez, o "barroco" serviria de parâmetro.

Foi com base numa concepção de origem que contém a idéia de salto em direção ao novo, como algo que se liberta e rompe com a continuidade num profundo processo de renovação, que os intelectuais do SPHAN fundaram as origens de uma produção artística autenticamente brasileira. Isso ficou bastante evidente no artigo em que Lucio Costa atribuiu esse salto qualitativo àqueles que denominou "renovadores" do século XVIII. ${ }^{37}$ As qualidades identificadas seriam as mesmas atribuídas à produção literária $\mathrm{e}$ arquitetônica modernista dos anos 20 e 30 - renovadora e revolucionária.

A valorização do vestígio e a preocupação em guardá-los para testemunhar à posteridade, foram estratégias visando estabelecer elos com um momento originário (barroco - século XVIII), que teria sido rompido e transformado. É, portanto, somente através do sentimento de pertencimento a um novo tempo (moderno - século XX) que se torna possível demarcar dois momentos precisos - o originário, que constitui a ancestralidade da nação, e o momento presente, de refundação, que é capaz de reconquistar o elo perdido constituinte do ser nacional, qual seja, o "espírito de in- 
venção", a "seiva criadora”, o "sentido plástico real" e a "espontaneidade" e reconhecer nesse gesto a ruptura. Lucio Costa carregava a crença de que a produção moderna da arquitetura resgataria essa que ele chamou de "a boa tradição". 38

A arquitetura era compreendida em todo seu conjunto, isto é, edificação e "arquitetura de interior" e, de acordo com as idéias que se (con)formavam a respeito do barroco no Brasil, esse estilo havia alcançado plenitude e maior liberdade de expressão, especialmente nas igrejas setecentistas mineiras, através da composição dos retábulos e das obras de talha.

Para inserir o Brasil na consagrada história da Arte Universal, investiu-se na reapropriação do barroco, que passou a ser visto como um movimento artístico considerado profundamente renovador, que desde a "pureza" e "verdade" das construções gregas jamais havia se repetido e que, a partir do barroco, só teve novo momento renovador com a arquitetura moderna, advinda da revolução industrial. Foi esta que possibilitou a invenção de novos materiais, novas formas e técnicas. A genialidade de Lucio Costa construía, assim, a genealogia da "boa arquitetura", universal, em que a produção brasileira se enquadrava, na origem e na atualidade

É certo que, além da universalidade visada, a arquitetura moderna brasileira conquistou também nesse momento a legitimidade de figurar como a produção nacional autêntica, herdeira legítima da boa arquitetura de renovação que deu origem a uma produção genuinamente brasileira. Ao mesmo tempo em que o SPHAN lutou pela consagração do barroco brasileiro, através de diferentes ações de seleção e proteção do patrimônio histórico e artístico, conseguindo tornar a produção artística brasileira parte integrante da produção universal da arte, investiu também em encontrar as especificidades do nacional nela contida. A produção artística brasileira foi reconhecida, porque inserida num processo civilizatório europeu percebido como universal - sendo este um traço marcante da concepção modernista dos três intelectuais - Drummond, Rodrigo e Lucio Costa. Os modernistas do SPHAN conquistaram a inserção do Brasil no mundo civilizado - assim como a inserção de sua própria produção artística que se tornou hegemônica - com o efetivo "ajuste dos relógios". Os tempos do sagrado se uniam. 
Se a memória é trabalho presente, é inevitável compreender que foi uma estética modernista que configurou o patrimônio histórico e artístico nacional. A arquitetura colonial foi privilegiada não somente pela sua ancianidade (valor comumente partilhado no âmbito da preservação cultural no mundo ocidental), mas porque foram-lhe atribuídas características que, segundo as concepçóes modernistas, distinguiam-na como primeiro momento de uma produção autenticamente nacional. Foi diferenciada, dessa forma, do que veio depois, considerado como importado (produção relativa ao século XIX e começo do século XX).

A "barroquização" do patrimônio histórico e artístico nacional implementada pelos modernistas foi, sem dúvida, uma impressionante estratégia de consagração de ambas as partes, que se tornaram constituintes do patrimônio histórico e artístico nacional. O conceito de barroco, bastante difuso, sempre foi perseguido como origem mítica de nossa nacionalidade.

O segundo momento de produção da "boa arquitetura" no Brasil deuse, para esses arquitetos do SPHAN, com a produção modernista, considerada autenticamente nacional e fundadora de uma nova temporalidade. Dessa forma, são os princípios norteadores da arquitetura moderna que identificavam uma genealogia da "boa arquitetura": ela seria, então, a herdeira da "boa tradição". Os atributos que caracterizariam a "boa arquitetura”, segundo as teses modernistas, qualificavam tanto a arquitetura tradicional brasileira, quanto a arquitetura moderna, constituindo, ambas, o patrimônio histórico e artístico nacional.

A estética modernista definia então a "boa arquitetura" e as características do patrimônio histórico e artístico nacional através de códigos compreendidos por aqueles que se formaram nessa experiência, tais como: beleza, autenticidade, harmonia, simplicidade, singeleza, graça, sobriedade. Não pretendiam destacar características de um "estilo barroco", mas sim da "boa arquitetura". Desta forma, o vocabulário constituinte do código do novo discurso em formação, engendrado a partir das restaurações, poderia ser atributo da arquitetura grega antiga, da arquitetura barroca colonial brasileira, e da arquitetura moderna.

A noção de patrimônio histórico e artístico nacional, constituída nos anos 30 e 40, consagrou-se, tornando-se reconhecida, vinculando o Brasil à civilização: nem exclusivamente o barroco, nem somente a arquitetura 
moderna, mas ambos enlaçados - trama e urdidura - constituíram o tecido "autenticamente nacional".

\section{Notas}

${ }^{1}$ Ávila, Afonso. "Saudação aos Congressistas”. Barroco. no 12, Belo Horizonte, 1982.

${ }^{2}$ Andrade, Rodrigo Melo Franco de. “Trigésimo aniversário da Semana de Arte Moderna; Rodrigo M. F. de Andrade recorda um manifesto que Sérgio Buarque perdeu." Diário Carioca, em 11/5/1952. In Rodrigo e seus tempos: coletânea de textos sobre artes e letras. Rio de Janeiro: MinC/SPHAN/Pró-Memória. 1986.

${ }^{3}$ Bom exemplo é o artigo de Sérgio Buarque de Holanda publicado na Revista do Patrimônio Histórico e Artístico intitulado "Capelas antigas de São Paulo". Revista do SPHAN no 5, 1941.

${ }^{4}$ Para um aprofundamento acerca da vertente modernista de Carlos Drummond de Andrade, ver Bomeny, Helena Bousquet. Guardiães da Razão. Modernistas mineiros. Rio de Janeiro: UFRJ/Tempo Brasileiro, 1994.

${ }^{5}$ Andrade, Rodrigo Melo Franco de. "Plínio Salgado; a anta e o curupira". Revista do Brasil, Rio de Janeiro, ano 1, v.9, 15/01/1927. In: Rodrigo e seus tempos: coletânea de textos sobre artes e letras. Rio de Janeiro: Ministério da Cultura, SPHAN, Fundação Nacional PróMemória, 1986, p. 230.

${ }^{6}$ Andrade, Rodrigo Melo Franco de. Op. cit. p.123.

${ }^{7}$ As principais proposiçôes de Mário de Andrade acerca da preservação do patrimônio cultural estão presentes claramente em seu Anteprojeto, que elaborou a pedido de Rodrigo Melo Franco de Andrade, para organização do novo serviço, em 1936. Embora pouco seguido, esse documento foi um interlocutor importante para que Rodrigo Melo Franco elaborasse o texto do Decreto-lei no 25, de 30 de novembro de 1937, que organizou a proteção ao "patrimônio histórico e artístico nacional", criando o instituto do tombamento, ainda hoje em vigor. Tanto o Anteprojeto de Mário de Andrade quanto o Decreto-lei 25/ 37 encontram-se publicados no livro Proteção e revitalização do patrimônio histórico e artístico no Brasil - um trajetória. Brasília: Fundação Nacional Pró-Memória, 1980.

${ }^{8}$ Bomeny, Helena Bousquet. Op. cit. p. 120/1.

${ }^{9}$ Carta de Rodrigo Melo Franco de Andrade a Lucio Costa, 18/7/1946 (Arquivo Noronha Santos - IPHAN - Pasta de Personalidades - Lucio Costa).

${ }^{10}$ A biblioteca e o arquivo do atual Instituto do Patrimônio Histórico e Artístico Nacional - IPHAN, denominados Noronha Santos, localizam-se no Palácio Gustavo Capanema, no Rio de Janeiro. A biblioteca reúne acervo especializado sobre história da arte, arquitetura, história, especialmente para o período colonial.

${ }^{11}$ Costa, Lucio. "Razões da Nova Arquitetura" [1934]. In: Lucio Costa: registro de uma vivência. São Paulo: Empresa de Artes, 1996. 
${ }^{12}$ Gregori Warchavchik era um arquiteto russo, nascido em 1897, que emigrou para o Brasil em 1923. Em 1925, Warchavchik lançava na imprensa paulistana seu Manifesto Acerca da Arquitetura Moderna. Foi o responsável pela primeira construção modernista no Brasil, sua residência em São Paulo, de 1927, tombada pelo IPHAN em 1986 (Processo de Tombamento no 1154-T-85, localizado no Arquivo Central do IPHAN). Sobre seu engajamento com o movimento da arquitetura moderna, ver Warchavchik, Gregori. Warchavchik e as origens da Arquitetura Moderna no Brasil. São Paulo: Museu de Arte de São Paulo, 1971.

${ }^{13}$ A respeito do revolucionário Salão de 1931, veja Vieira, Lucia Gouveia. O Salão de 1931. Rio de Janeiro: Funarte, 1984.

${ }^{14}$ Koatz, Eduardo. O processo de Criação da Faculdade Nacional de Arquitetura e de seu Currículo. Rio de Janeiro. Dissertação (Mestrado em Educação) - UFRJ, 1996.

${ }^{15}$ Decreto federal no 23.569/33, sendo que permanecia a garantia do exercício das funções de arquitetos, arquitetos-construtores e agrimensores aos profissionais não diplomados, mas licenciados pelos Estados e Distrito Federal, se provado o exercício à data da publicação do decreto. Cf. Legislação do Exercício da Engenharia, Arquitetura e Agrimensura. 1947. Conselho Federal da Engenharia e Arquitetura, 1947.

${ }^{16}$ A história desse episódio já foi tratada, com vasta documentação, por Lissovsky, Maurício e Sá, Paulo. Colunas da Educação: a Construção do Ministério da Educação e Saúde. Rio de Janeiro: IPHAN, 1996 e também por Cavalcanti, Lauro. As Preocupaçôes do Belo. Rio de Janeiro: Taurus, 1995.

${ }^{17}$ A Faculdade Nacional de Arquitetura, oriunda da Escola Nacional de Belas Artes, foi criada em 1945; a Faculdade de Arquitetura Mackenzie, separada da Escola de Engenharia Mackenzie, surgiu em 1947; a Faculdade de Arquitetura e Urbanismo da Universidade de São Paulo, separada da Escola Politécnica, em 1948; a Faculdade de Arquitetura da Universidade do Rio Grande do Sul, oriunda do Instituto de Belas Artes, em 1952; a Faculdade de Arquitetura da Universidade Federal da Bahia, originária da Escola de Belas Artes da Bahia, em 1959, juntamente com a Faculdade de Arquitetura da Universidade Federal de Pernambuco. Sobre o assunto, cf. Sobre a História do Ensino de Arquitetura no Brasil. São Paulo: Associação Brasileira de Escolas de Arquitetura, 1977.

${ }^{18}$ Sobre a constituição de um habitus advindo da formação escolar e a construção de mecanismos de prestígio e promoção através da formulação de discursos e práticas de reconhecimento e pertencimento/exclusão ver BOURDIEU, Pierre. A Economia das Trocas Simbólicas. São Paulo: EDUSP, 1982.

${ }^{19}$ Conforme colocou Ítalo Campofiorito, integrante da equipe de arquitetos construtores de Brasília - "Nova Cap", no artigo "O patrimônio cultural: um balanço crítico". Revista do Brasil-ano 2, no 4, 1985. Governo do Estado do Rio de Janeiro/Secretaria de Ciência e Cultura, Prefeitura do Rio de Janeiro. Confira também a Apresentação do autor ao livro de Lissovsky, Maurício e Sá, Paulo. Op. cit..

${ }^{20}$ Augusto Carlos da Silva Telles foi arquiteto do IPHAN, desde a década de 1950, e professor da faculdade de Arquitetura e Urbanismo da UFRJ. Foi diretor da Diretoria de Tom- 
bamento e Conservação do IPHAN por longos anos. No final da década de 1980 ocupou, por curto período, o cargo de presidente da Fundação Nacional Pró-Memória e de secretário da então Secretaria do Patrimônio Histórico e Artístico Nacional - SPHAN.

${ }^{21}$ Telles, Augusto Carlos da Silva. Barroco no Brasil: análise de sua bibliografia crítica e colocação de pontos de consenso e de dúvidas. Lisboa: Academia Nacional de Belas Artes, 1979 , p. 15.

${ }^{22}$ Telles, Augusto C. da Silva. Op. cit., p. 14.

${ }^{23}$ Telles refere-se aos seguintes artigos: Cardoso, Joaquim. Um tipo de casa rural do Distrito Federal. Revista do SPHAN no 7, 1943; Saia, Luiz. Notas sobre a arquitetura rural paulista do segundo século. Revista do SPHAN no 8, 1944; Barreto, Paulo Thedim. Casas de Câmara e Cadeia. Revista do SPHAN no 10, 1946; e, especialmente o de Costa, Lucio. Arquitetura jesuítica no Brasil. Revista do SPHAN no 5, 1941, que será tratado em particular.

${ }^{24}$ Seus artigos publicados na Revista do SPHAN foram: "Alguns desenhos de arquitetura existentes no Arquivo Histórico Colonial Português" (no 4/1940); "O códice de frei Cristóvão de Lisboa”(n5/1941); "Documentos baianos” (no 9/1945). Seu último artigo, intitulado "Arquitetura civil do período colonial", saiu no no 17/1969, teve caráter de síntese, ao contrário dos anteriores, mais monográficos.

${ }^{25}$ Andrade, Rodrigo Melo Franco de. Op. cit.

${ }^{26}$ A Manhãa, de 21 de janeiro de 1946, apud Andrade, Rodrigo Melo Franco de. Op. cit., p. 22.

${ }^{27}$ Andrade, Rodrigo Melo Franco de. Programa. Revista do SPHAN, no 1/1937.

${ }^{28}$ Freyre, Gilberto. Sugestões para o Estudo da Arte Brasileira. Revista do SPHAN no 1 , 1937, p. 41.

${ }^{29}$ Andrade, Mário. A Capela de Santo Antônio. Revista do SPHAN no 1, 1937, p. 119.

${ }^{30}$ Costa, Lucio. Documentação Necessária. Revista do SPHAN no 1, p. 34.

${ }^{31}$ Vale registrar, ainda, a presença de Heloísa Alberto Torres, Diretora do Museu Nacional, com o artigo "Contribuição para o estudo da proteção ao material arqueológico e etnográfico no Brasil”. Revista do SPHAN, no 1.

${ }^{32}$ Costa, Lucio. “Arquitetura jesuítica no Brasil”. Revista do SPHAN no 5, 1941, p. 12.

${ }^{33}$ Costa, Lucio. Op. cit..

${ }^{34}$ Ibidem, p. 9.

${ }^{35}$ Ibidem, p. 13.

${ }^{36}$ Ibidem, p. 47.

${ }^{37}$ Ibidem.

${ }^{38}$ Costa, Lucio. Op. cit., 1937. 


\section{Resumo}

O artigo aborda as concepçôes que fundamentaram as práticas brasileiras de preservação cultural, especialmente relacionadas ao pertencimento à civilização ocidental, consagrado pela associação inédita entre as formas e princípios renovadores do barroco e a produção arquitetônica moderna. Essa associação será fundamentada pela noção de universalidade da arte e da cultura brasileiras, partilhada por modernistas como Rodrigo Melo Franco de Andrade, Carlos Drummond de Andrade e Lucio Costa, como funcionários do Serviço do Patrimônio Histórico e Artístico Nacional.

Palavras-chave: arquitetura moderna; barroco; identidade nacional; Lucio Costa; modernismo; patrimônio cultural.

\section{Abstract}

This article analyzes the main practices of cultural preservation in Brazil, specially those that concern the Western civilization, consecrated by the association of forms and principles of the baroque and the modern artistic production. This association is based on the notion of universality of the brazilian art and culture, shared by modernists such as Rodrigo Melo Franco de Andrade, Carlos Drummond de Andrade and Lucio Costa, functionaries of the Serviço do Patrimônio Histórico e Artístico Nacional. Key-words: modern architecture; baroque; national identity; Lucio Costa; modernism; cultural patrimony. 